\title{
As roupas destinadas aos exercícios físicos e ao esporte: nova sensibilidade, nova educação do corpo (Brasil, 1920-1940)
}

Carmen Lúcia Soares

Resumo: As roupas possuem lugar privilegiado na história da humanidade e sua especificidade sexual, étnica, religiosa, política ou cotidiana, revela esse lugar. A vestimenta constitui característica fundamental dos seres humanos, e o ato de vestir-se obedece a determinaçóes sociais, sendo resultado de um laborioso processo de transformação de sensibilidades em relação ao corpo e a sua exibição; de tolerância à nudez e à natureza corporal. Este trabalho dedica-se ao levantamento, à seleção e à análise de reportagens e imagens publicadas em revistas brasileiras pertencentes ao domínio da educação física e do esporte entre os anos de 1920 e 1940 e tem como objetivo compreender as justificativas elaboradas para o uso de roupas específicas nessas práticas, em suas dimensões higiênicas, morais e estéticas, presentes nos argumentos desenvolvidos no período. As fontes trabalhadas são três revistas publicadas no Brasil no período delimitado para este estudo.

Palavras-chave: educação do corpo; roupas esportivas; higiene corporal.

\section{Clothes for physical activities and sports: new body awareness and education (Brazil, 1920-1940)}

Abstract: The clothes occupy a privileged place in the history of humanity and its sexual, ethnic, religious, political or daily specifics reveal this positioning. A piece of clothing constitutes a fundamental human being attribute and the act of dressing obeys social determinations, which are the result of a laborious process of awareness transformation related to the body and its exposure, the tolerance to nudity and body nature. This work aims to locate, select and analyze articles and images published in Brazilian newspapers that belong to the domain of Physical Education and Sports between the years of 1920 and 1940 and seeks to understand the reasons for the use of specific clothes in these practices in their hygienic, moral and aesthetic dimensions, present in the arguments developed in that period. The analysed sources consist in three magazines published in Brazil during the period delimited for this study.

Key words: body education; sportswear; body hygiene.

Professora Assistente Doutora da Universidade Estadual de Campinas, SP, Brasil. carmenls@ unicamp.br 


\section{I-As roupas e a educação do corpo}

As roupas ${ }^{1}$ afirmam traços humanos, revelam pertencimentos ou exclusões, assim como diferenças entre uma natureza corporal e as marcas da cultura. Elas constroem, compõem, fabricam as aparências, contam trechos das histórias miúdas, cotidianas, banais, como escreveu Roche (1997), e permitem que aspectos da vida em sociedade sejam compreendidos de maneira mais profunda. Fabricam necessidades, instituem formas de proteção e conforto, mas também alimentam a artificialidade, o sonho, a sedução e, de maneira constante e sistemática, constituem, em profundidade, uma educação do corpo.

$\mathrm{Na}$ história da humanidade as roupas certamente possuem um lugar bastante privilegiado, e sua especificidade étnica, religiosa, política ou mesmo cotidiana, sem dúvida, revelam esse lugar. Cobrir ou adornar o corpo nu constitui traço de distinção, e cada cultura e sociedade tratará de marcar sua singularidade também por esse gesto, uma vez que as roupas se apresentam explicitamente como marcadores sociais e sexuais, permitindo julgar, aceitar ou excluir indivíduos e grupos. $\mathrm{O}$ ato de vestir-se obedece, assim, a determinaçôes sociais específicas e revela-se como resultado de um laborioso e lento processo de transformação de sensibilidades em relação ao corpo e à sua exibição; de tolerância à nudez e à "natureza" corporal. A anatomia primeira é sempre considerada como inaceitável, ameaçadora e "[...] o corpo não fala senão quando ele é coberto de artifícios” (Borel, 1992, p. 16). Como escreveu Balzac (2004, p. 61, grifo nosso), um homem nu é assustador "[...] Porque, quando se diz homem, na civilização, se diz homem vestido".

A função de proteção do corpo dada pela roupa, elementar, sem dúvida, pode ser considerada como aquela que permite vislumbrar outras características e particularidades. Roche (1989), analisando discursos acerca dessa função, sugere que ali é possível encontrar um leque de racionalidades e significaçóes diversas e, entre elas, aquela elaborada pelos médicos que, entre os séculos XVII e XX, faziam das roupas um elemento importante nos cânones da saúde, alertando, entre outros aspectos, para os benefícios e os perigos da exposição do corpo ao ar e, principalmente, ao sol $^{2}$.

Essa mesma função atribuída à roupa pode também ser analisada desde outra significação, que não aquela física, carnal, mas, sim, moral, ou seja, a de proteger

I. Falamos aqui especificamente das roupas, mas poderíamos nos referir também aos ornamentos, às pinturas, a todas as marcas da cultura que incidem sobre o corpo, "vestindo-o" de traços culturais singulares.

2. A exposição do corpo ao sol foi objeto de grande interesse de médicos e educadores desde o século XVIII, mas seria somente no século $X X$ que a compreensão e a aceitação da pele bronzeada como sinônimo de beleza teriam lugar no Ocidente. A beleza pigmentária à ocidental era da ordem do mármore e, no século $X X$, ela passou a ser aquela do bronze. Ver, a respeito, Andrieu (2008); Andrieu et al. (2008), Lanoë (2008); Ory (2008), entre outros.

Pro-Posições, Campinas, v. 22, n. 3 (66), p. 81-96, set./dez. 2011 
o corpo do olhar do outro ${ }^{3}$. Desde textos sagrados como, por exemplo, a Bíblia, no Gênesis (cap. III, IV, p. 5), vamos encontrar claramente uma alusão a outra significação de proteção, quando lemos "[...] e, percebendo que estavam nus coseram folhas de figueira e fizeram cintas para si...". Podemos reafirmar que o gesto de cobrir o corpo, seja com roupas, seja com adornos diversos, seja mesmo com pinturas, é um traço fundamental de civilização, de diferenciação do ser humano de outros elementos da natureza, como animais e mesmo plantas. Entretanto, esse gesto aparentemente banal de cobrir o corpo com roupas, de protegê-lo e de proteger-se do olhar do outro nem sempre é condição humana respeitada. Seguidamente a nudez indesejada surge ameaçadora em regimes totalitários, em prisões e campos de concentração, locais onde, entre as humilhações sofridas, encontramos sempre a privação de roupas (Oliva, 2001). Esse ato de violência revela, claramente, as relaçôes de poder implícitas no ato de vestir-se e, sobretudo, na ambivalência dessa suposta liberdade.

Gesto civilizatório singular, o ato de vestir-se revela-se também como valor informativo e expressa posição social, pertencimento ao gênero humano repartido em sexo, idade, classe social, cultura, condiçôes sanitárias, costumes, posições político-ideológicas e religiosas (Mottiaux, 2005). A indumentária possui íntima relação com os costumes de cada época e de cada sociedade, balizando todo um percurso do que é útil e do que é inútil, do que possui um valor de mercado e do que possui um valor de uso (Roche, 1989).

Elemento da cultura material, as roupas representam também uma acumulação de conhecimentos científicos, de técnicas e de tecnologias e são uma resposta humana às agressōes do meio. Elas participam da construção de uma sensibilidade mais aguda, reveladora da formação de um julgamento moral e são, paradoxalmente, uma maneira de esconder e de exibir o corpo, compondo aquilo que Bologne (1986) chamou de panóplia da sedução.

Seria possível inferir que as roupas permitem pensar o sensível e todas as relações entre os indivíduos e os objetos, inserindo-se, portanto, na história do corpo, da beleza, e também na história da educação, da saúde, da higiene, do mercado e do consumo; uma história que, segundo Roche (1989), escapa às datações fáceis e aos recortes temporais habituais. Elemento formal, normativo, simbólico, sem dúvida, a roupa permite a compreensão das transformações e do funcionamento de uma dada sociedade ; elas são "...como as palavras de uma língua que é necessário traduzir e explicar” (Roche, 1989, p. 48).

3. Conforme as análises de Jean-Claude Bologne, em Histoire de la pudeur (1986); Yvonne Deslandres (1990), em "Les modes vestimentaires dans la société occidentale"; e Frédéric Monneyron, em La mode et ses enjeux (2005). 
Em sua fragilidade e efemeridade como objeto, testemunham também a passagem do tempo e os modos como homens e mulheres se envolvem com o mundo material, com as negociaçôes da vida cotidiana, com sua natureza corpórea, uma vez que a "... relação entre comportamento e mundo material está longe de ser passiva. Os artefatos são encarnações tangíveis das relações sociais, incorporando atitudes e comportamentos do passado" (Beaurdry; Cook; Mrozowski, 2007, p. 73). Indicam, assim, maneiras de viver, pertencimento. $O$ desaparecimento veloz de uma roupa, de um utensílio qualquer, a impossibilidade de armazenamento desses múltiplos e variados objetos, seja pela ausência de espaço, seja pela precariedade das moradias, dos locais de trabalho e de divertimento, seja mesmo pela fragilidade de sua confecção, são indicadores de valores, de atenção, de sensibilidades de outros tempos. Os objetos, em sua aparente banalidade, expressam e revelam os quadros mentais mais amplos das sociedades a que pertenceram. Como artefatos, as roupas estão na base da criação de comportamentos, pela capacidade mesma que possuem de afirmar identidades sociais já latentes (Crane, 2006).

Marcadores de uma das formas mais visíveis do consumo, as roupas, assim, atestam e revelam claramente o aumento do padrão de vida de uma dada sociedade e de um período e fazem parte de uma esfera mais leve da vida, ligada ao supérfluo, que, conforme afirma Simmel (2008, p. 62), não deve ser negligenciado, pois é algo que "... 'sobeja', vai além do seu ponto de partida [...] estende à volta do recinto da simples necessidade uma região mais ampla [...] ilimitada".

Daí porque ser possível pensar nos objetos, entre eles, as roupas, mas também os adornos em geral— quer destinados ao corpo, quer destinados ao ambiente —, como poderosos elementos de manutenção ou de subversão de fronteiras simbólicas que indicam como os indivíduos, em épocas distintas, percebem a si próprios, sua posição nas estruturas sociais, nas negociaçôes de status, nos lugares em que se veem, que almejam e em que podem ou não estar. É assim, por exemplo, que os processos de distinção e de afirmação de lugares sociais vão sendo também determinados pela roupa, o que contribui para o alto valor que ela ocupa como marcador social, como traço de distinção de classe. A distinção, como assinalou Bourdieu (2007), expressa-se em detalhes e, especialmente, em coisas aparentemente banais. Daí ser apropriada uma aproximação com o debate acerca do fenômeno moda na vida em sociedade. Simmel (1989) sublinha a estreita relação entre vida urbana, individualismo e moda nas sociedades industriais.

Simmel (1905), já no início do século XX, pensava a moda como manifestação privilegiada da realidade social e ressaltava que "[...] o modo de andar, a cadência, o ritmo dos gestos são, sem dúvida, essencialmente determinados pelo vestuário; homens vestidos de modo semelhante comportam-se de modo relativamente semelhante" (Simmel, 2008, p. 29-30).

Pro-Posições, Campinas, v. 22, n. 3 (66), p. 81-96, set./dez. 2011 
Vê-se aqui uma clara alusão a uma educação do corpo e dos comportamentos associados ao modo de vestir-se, a um desejo de pertença, de partilha, mas, ao mesmo tempo, de isolamento, de individuação. As modas do que se veste e quando se veste, seja pela disponibilidade ou não de roupas em bom estado, seja pela especificidade de seus usos permitem e instigam um movimento constante de indivíduos e grupos em direção a processos imitativos, mas, ao mesmo tempo, a processos e desejos de distinção. Como imitação, ela empresta ao indivíduo a sensação de apoio coletivo, de pertença; como distinção, ela se nutre da necessidade da separação, da mudança. O que marca a moda é, sem dúvida, a mudança constante de conteúdos; ela é, pois, como assinalou Simmel (2008, p. 25), “[...] um produto da divisão de classes".

Também Walter Benjamin (2007) não é indiferente ao fenômeno moda e, ao pensar a cidade, assinala a roupa como elemento de distinção, como traço de classe, ou, ainda, como elemento que marca a singularidade das atividades humanas.

Quando se supera o imediato, a necessidade primeira de proteção de um corpo $\mathrm{nu}$, surgem outras dimensōes a serem exploradas para compreender não apenas os usos, mas, também, as maneiras de confeccionar as roupas, os lugares e as horas de seus usos, a exposição e o ocultamento de partes do corpo, as cores e as texturas. Seria possível pensar que há uma percepção da sociedade e do indivíduo de que as roupas, sua confecção e também as maneiras de vestir-se evoluem ${ }^{4}$ conforme ritmos bastante próprios, e suas variações revelam mais que uma história das modas, mesmo porque elas, as modas, são constitutivas de extensos e intensos processos econômicos, sociais e culturais, de todo um sistema da civilização material, e não poderiam ser dele isoladas.

\section{2-Os lugares, o tempo e as roupas esportivas: as revistas especializadas}

A partir de uma leitura de reportagens, da publicidade e de imagens relativas aos usos de roupas específicas destinadas às práticas corporais e esportivas, publicadas em três periódicos especializados do campo da educação física e do esporte, este artigo busca compreender as justificativas higiênicas, morais e estéticas presentes nos argumentos concernentes ao uso de roupas específicas para essas atividades, desenvolvidos no período. Abundantes na imprensa nas primeiras décadas do século XX, esses argumentos e recomendaçōes eram postulados como medida higiênica,

4. Charles Darwin, conforme relata Daniel Roche (1997, p. 209), afirmava, em 1900, que a "[...] roupa é submetida à lei do progresso e as modas se sucedem numa continuidade quase perfeita. Nos dois casos, uma forma é substituída por uma outra que é melhor adaptada às condições ambientes do momento".

Pro-Posiçôes, Campinas, v. 22, n. 3 (66), p. 81-96, set./dez. 2011 
estética e, em menor escala, também, performática. Assim, as fontes desta pesquisa foram constituídas por três periódicos publicados no Brasil entre as décadas de 1930 e 1940: a) Educação Physica: Revista Thécnica de Sports e Athletismo5 ; b) Revista de Educação Física; a) Sport Illustrado.

O período delimitado para a pesquisa ${ }^{6}$, aqui apresentada em alguns extratos, compreende os anos de 1920 a 19407 , época de profunda transformação na sociedade brasileira e na cultura vestimentar, que põe em movimento uma nova sensibilidade e um novo estilo de vida urbano, o estilo esportivo.

\section{3-Vestindo corpos, descobrindo sentidos: as roupas especiais como necessidade}

As roupas utilizadas com especificidade nas práticas corporais e esportivas constituem-se como resultado de uma especialização de discursos sobre a educação do corpo e suas performances e, ao mesmo, respondem às alterações em relação à tolerância da exibição de um corpo nu (Barthe-Deloizy, 2003).

Num quadro de valorização do corpo e da prática de exercícios físicos e esportivos como medida higiênica e profilática, as roupas específicas a ela destinadas particularmente desde os anos de 1920, inseriram-se também no campo da higiene, uma vez que seus usos eram recomendados por médicos, pois fornecem vigor e potencializam energias curativas. Sua confecção, portanto, deve considerar o uso de tecidos leves que permitam ao corpo "respirar"; num certo sentido, as roupas desse período inauguraram uma "moda do natural" e do "higiênico", que, paula-

5. Este periódico sofreu modificações na grafia de seu nome ao longo dos anos de sua circulação. Em estudo detalhado sobre ele, Samuel Neto (2004) assim resume as modificações ocorridas no nome: "quando de publicação inicial foi denominada EDUCAÇÃO FÍSICA/PHYSICA - Revista Téchnica de Sports e Athletismo (1932/ n I - 1937/ n I0); em seguida, passa a chamar-se EDUCAÇÃO FíSICA - Revista Téchnica de Esportes (1937/ n० II - 1937/n 12); EDUCAÇÃO FíSICA - Revista Téchnica de Esportes e Saúde (1937/ n 13 - 1938/n 14) e, finalmente, EDUCAÇÃO FíSICA - Revista de Esportes e Saúde (1938/n I5 - 1945/n 88)" (p. 4-5). Neste artigo citaremos o periódico de acordo com as mudanças ocorridas em seu nome.

6. Tese de Livre-Docência realizada na Unicamp sob o título "As roupas nas práticas corporais e esportivas: a educação do corpo entre o conforto, a elegância e a eficiência (1920- 1940)", em outubro de 2010.

7. Uma delimitação temporal sempre extrapola os limites mentais que impomos, uma vez que está sempre sujeita à lentidão com que ocorrem as mudanças numa dada sociedade cujas práticas e cujos discursos se deseja compreender. Ver, entre outros, Braudel, 1992.

8. Ver, por exemplo, as pesquisas realizadas por Sandrine Jamain, especialmente, 2005, e Jamian e Terret, 2009; Victor Andrade de Melo. Cidade Sportiva. Rio de Janeiro: Relume Dumará/FAPERJ, 200 I; Vitor Andrade de Melo. Moda. In: Dicionário do Esporte no Brasil, 2007; Ricardo Figueiredo de Lucena. O esporte na cidade, 200I, ambos publicados em Campinas, pela editora Autores Associados.

Pro-Posições, Campinas, v. 22, n. 3 (66), p. 81-96, set./dez. 2011 
tinamente, foi se afirmando nas cidades e fazendo parte de uma nova sensibilidade e de um novo modo de vida urbano?.

Seria possível dizer que a estrutura do corpo passou a ser mostrada e destacada pela roupa, possibilitando também maior liberdade de movimento, uma vez que o peso de adornos até então usuais, como o espartilho e saltos muito altos, foi, de certo modo, diminuído e mesmo abandonado. Também os cabelos, antes sempre muito longos, podiam agora ser usados curtos. ${ }^{10}$ Elegeram-se, assim, corpos reais, e as roupas das mulheres revelavam certa liberdade, alcançada, também, pela sua confecção com tecidos leves, aderentes ao corpo e com transparência. Até mesmo as calças compridas, que guardavam ainda muitas restriçóes de uso, eram toleradas ${ }^{11}$. Os tecidos em voga no período apresentavam-se, assim, como uma extensão da pele e acompanhavam os movimentos do corpo, em uma composição tangível e plástica. Os tricôs macios, as lãs e as sedas eram utilizados abundantemente, e muitos de seus modelos copiavam, literalmente, aqueles já utilizados em práticas esportivas, como, por exemplo, os trajes de montaria. As roupas desse período foram largamente inspiradas nos movimentos do corpo e fizeram, mesmo, surgir também a ideia de conforto ${ }^{12}$.

Seria possível afirmar que, nos anos de 1920, as roupas emolduravam as formas corporais de um modo muito mais intenso e contribuíram para a transformação de valores morais e estéticos. Assim, as formas redondas e cheias, consideradas apropriadas às mulheres foram ali negadas, e o corpo feminino que surgiu como modelar era esguio e associado aos valores da velocidade e das modernas máquinas, de sua nova aerodinâmica. As observações do biólogo francês Georges Demeny, entusiasta da educação do corpo feminino pelos exercícios físicos, já na década de $1920,{ }^{13}$ revelam uma compreensão do lugar das roupas na educação do corpo. Naquele período, ele escrevia que o "traje valoriza o encanto das linhas e a natu-

9. Ver, entre outros: Georges Vigarello. Histoire de la beauté: le corps et l'art d'embellir de la renaissance à nos jours. Paris: Seuil, 2002.

10. Também os cabelos podem ser usados curtos, quase raspados, seguindo a moda "à la garçonne". Na literatura, temos o grande sucesso, em 1922, do romance de Victor Margueritte, La garçonne, Paris, Flammarion, obra que vendeu mais de um milhão de exemplares e dá uma visão bastante diferente da mulher de então: menos meiga e delicada, mais altiva e combativa.

1 I. O uso corrente e sem preconceitos da calça comprida, em qualquer ambiente, só ocorreu na década de 1960, quando as mulheres, por exemplo, mesmo usando essa peça vestimentar, não eram mais impedidas de entrar em bares, restaurantes e outros estabelecimentos. Ver, a respeito, entre outros, BARD, Christine. Une histoire politique du pantalon. Paris : Seuil, 2010.

12. Ver, a respeito: HOLLANDER, Anne. O sexo e as roupas. Rio de Janeiro: Rocco, 1996, especialmente o capítulo IV.

13. A obra intitula-se Education et harmonie des mouvements; trabalhamos aqui com sua $7^{\text {a }}$. edição, publicada por Felix Alcan, Paris, 1920. Demeny teve grande influência sobre o pensamento da educação física no Brasil, seja entre educadores, como, por exemplo, Fernando de Azevedo, seja entre médicos. 
ralidade do gesto; para isso, a roupa deve ser moldada pelo corpo e não o corpo pela roupa" (1920, p. 5).

\section{4-A roupa esportiva e os seus desafios: do conforto à higiene, da elegância à performance, trechos de um breve percurso}

Seria necessária outra sensibilidade para que o sentimento de conforto (Sant'Anna, 2000) estivesse associado às roupas e, mais especificamente, a certo tipo de roupa voltado especificamente a um conjunto de atividades, como o ato de exercitar-se e de demonstrar performances corporais que, lentamente, foram sendo definidas como "esportivas".

Se a função de proteção nunca é abandonada, outras são a ela agregadas e parecem ganhar importância, na medida mesma da afirmação da vida urbana e da especialização de funções e tarefas. Vestir-se com especificidade para atividades distintas torna-se, assim, desejo de muitos, busca constante, necessidade nova afirmada. Com as roupas destinadas aos exercícios físicos e ao esporte não foi diferente, e esses modelos que iriam influenciar a moda de uma maneira geral criaram, assim, um estilo, evocando proteção, facilidade de uso, conforto - em uma palavra: liberdade! Note-se, portanto que o esporte também se adjetiva nas roupas, e, se uma roupa esportiva é desenhada e vendida, se ela gera um mercado específico para ambos os sexos, ela gera, também, distinção entre os sexos. Assim, para as mulheres, a moda em geral — e mesmo a moda esportiva — foi sempre mais enfática no quesito "elegância".

A revista Sport Illustrado, em seu número 19, de agosto 1938, apresenta alguns modelos de roupas especiais destinadas à prática esportiva de ambos os sexos, mas, quando se refere às mulheres, afirma que

$$
\begin{aligned}
& \text { qualquer que seja a resposta, o certo é que já constitue uma } \\
& \text { preocupação universal, a attenção dos technicos para os } \\
& \text { trajes femininos, que melhor se prestem às encantadoras e } \\
& \text { caprichosas sportwomen, mais severas nas exigências revela- } \\
& \text { doras do bom gosto e do raffinement da arte de vestir com } \\
& \text { elegância e it, do que mesmo no treino e pratica do sport a } \\
& \text { que entenderam dar preferência [...] }
\end{aligned}
$$

A imagem de mulheres velejadoras na capa da revista de $n^{\circ} 6$, de maio de 1938 , revela também a sintonia de suas praticantes com a moda esportiva; elas estão vestidas com impecáveis pantalonas e saias-calça, com sapatos bem confortáveis, de tipo alpercatas, como se pode ver na Figura 1.

Algumas peças de roupa, além das calças compridas, foram bastante revolucionárias no quesito conforto, sendo a saia-calça um bom exemplo. Ela foi bastante 


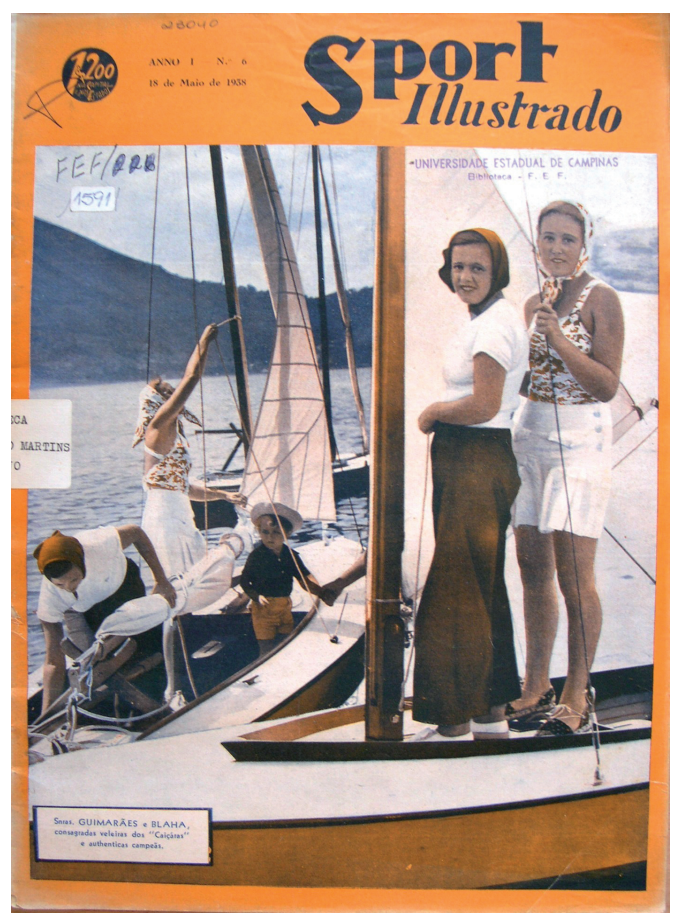

Figura I- Capa

Fonte: Sport Illustrado, n. 6, 1938.

usada desde fins do século XIX, em diferentes modalidades esportivas e até mesmo em um simples passeio de bicicleta. A revista Sport Ilustrado, em seu número 19, sublinhou a necessidade de utilizar roupas especiais para passeios de bicicleta e, em artigo intitulado "Trajes Sportivos: a moda no sport ou o sport na moda?", apresentou três modelos de trajes sportivos para uso nesses passeios.

Educação Física: revista de esporte e saúde, em seu n ${ }^{\circ} 38,1940$, publicou artigo intitulado "Higiene culturista da mulher-Esporte benéfico: a bicicleta", em que acentua a necessidade de roupas especiais para sua prática, detalhando, inclusive, sua adequação às estaçôes do ano. Assim, "[...] No verão, esse esporte pedirá roupas leves que permitam o arejamento rápido do corpo [...] No inverno, exigirá lãs que protejam do ar frio [...] [...] Não deverá usar roupa de montanha" (p. 39, 67).

Ou, ainda, em seu número 49, também no ano 1940, no artigo intitulado "Ciclismo, um esporte agradável e utilitário: sua historia e sua prática", cujo conteúdo confere destaque ao uso de roupas especiais para essa prática, afirma que "[...] o uniforme deve ser simples, de forma a não dificultar os movimentos e não impedir a boa circulação; é aconselhado calção, camisa sem mangas, sapatos de lona e uma 'rede' para prender o cabelo" (p. 19). 


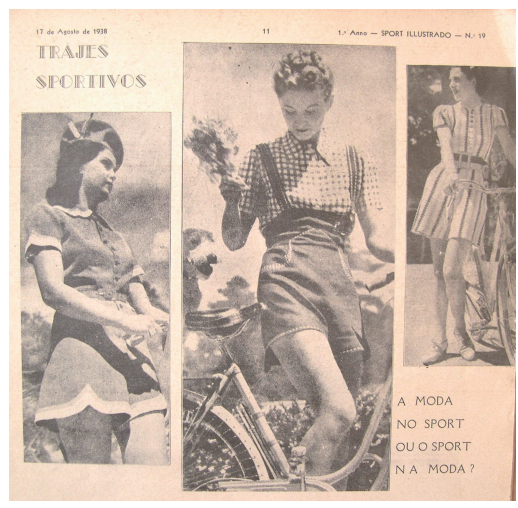

Figura 2 - Trajes esportivos

Fonte: Sport Illustrado, n. 19, p. II, 1938.

A prática do ciclismo ${ }^{14}$ foi muito aceita desde fins do século XIX, sobretudo nas primeiras décadas do século XX, movimentando tanto o mercado de bicicletas, quanto o de roupas especiais para sua prática.

Outra modalidade esportiva que expressa também as tendências dos usos de roupas especiais no esporte é o tênis. Os uniformes masculinos e femininos elaborados para essa modalidade sofreram inúmeras alterações no período estudado e conviveram em suas diferenças, sendo o comprimento das saias para as mulheres, ou das calças para os homens um bom exemplo dessa diversidade de usos. No mesmo momento em que as saias foram encurtadas, os homens começaram a jogar tênis de shorts, no lugar das calças compridas, que até esse período eram as únicas aceitas para esse esporte. Também as camisetas por eles utilizadas perderam centímetros de pano ao longo dos anos, conferindo um tom mais atlético aos seus praticantes. Poderíamos dizer que a roupa acentua, sublinha, revela o vigor do corpo.

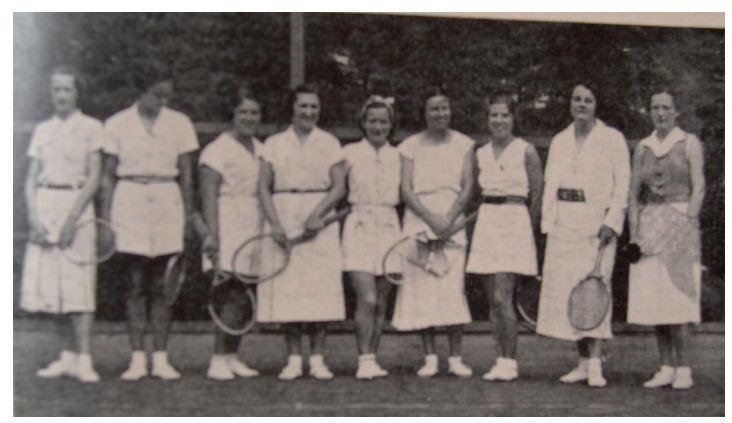

Figura 3 - Tenistas de Juiz de Fora-MG

Fonte: Revista EducaçãoPhysica - Revista de Esportes e Saúde, n. 16, 1938.

14. Ver, a respeito, Melo, 2009, p. 7 I a 105.

Pro-Posições, Campinas, v. 22, n. 3 (66), p. 81-96, set./dez. 2011 
O hipismo, praticado por homens e mulheres, é um esporte que influencia largamente a moda em geral. Em seu $n^{\circ} 19$, Sport Illustrado exibiu, em sua página 28 , extensa reportagem, com praticantes da modalidade de ambos os sexos, elegantemente vestidos com seus uniformes.

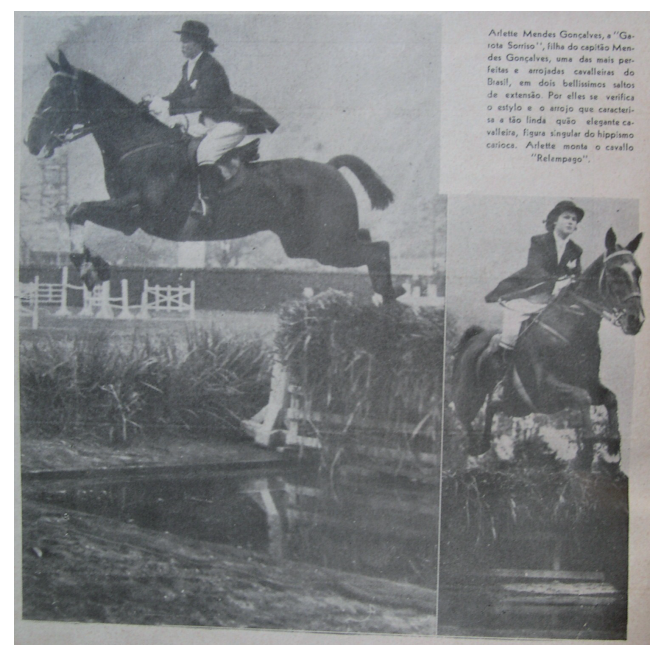

Figura 4 - Equitação feminina

Fonte-Sport Illustrado, n. 18, 1938, p. 10.

A revista Sport Illustrado dava ênfase, em suas páginas, não apenas aos modos de vestir próprios dos praticantes das modalidades que compunham o espetáculo esportivo, mas, também, da plateia, sublinhando a elegância do público presente nos eventos. Em seu número 17, de 1938, a revista mostra a festa hípica do Fluminense com fotos de sua plateia, chamando a atenção para "a elegância das senhoras".

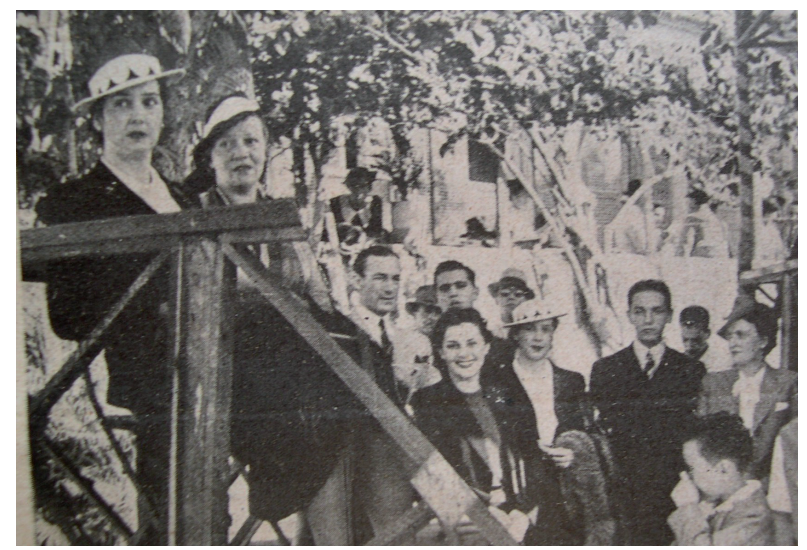

Figura 5- Espectadoras de evento esportivo. Fonte: Sport Illustrado, n. 17, 1938 
Se a prática de exercícios físicos e de esportes fora antes realizada com roupas comuns, como, por exemplo, roupas de verão, ou mesmo as saias longas e rodadas utilizadas largamente para a prática do tênis entre as mulheres, o período analisado nesta pesquisa marca, de maneira bastante evidente, um processo de ruptura, invertendo lógicas e valorizando, de maneira profunda, aquilo que se veste com especificidade no esporte.

Assim, as saias, uma vestimenta quase universal nesse período, sofreram um progressivo encurtamento, atestando, de certo modo, uma busca de exposição seletiva do corpo pelas próprias mulheres. Talvez o encurtamento das saias para a prática do tênis, já na década de 1920, tenha sido mesmo a grande revolução em relação às roupas femininas em geral ${ }^{15} \mathrm{e}$ àquelas específicas para a prática de esporte.

O futebol também surgiu, nas páginas das revistas analisadas, como prática corporal possível para as mulheres, e os equipamentos necessários, entre eles, a roupa especial, foram mencionados por Educação Física: Revista de Esporte e Saúde, em seu número 46, de 1940, no artigo intitulado "Pode a mulher jogar o futebol?". O conteúdo do artigo pondera com argumentos favoráveis e contrários a essa prática para as mulheres e, em sua conclusão, é favorável à possibilidade da prática por elas, desde que observadas certas precauçôes como: "[...] usar sapatos de borracha evitando chuteiras comuns; [...] uniformes apropriados, limpos e folgados, que não [...] embaracem a amplitude dos movimentos; evitar os jogos em certos períodos; etc..." (p. 18, 19 e 20).

Seria adequado ressaltar aqui que as justificativas higiênicas compareciam seguidamente, quando se tratava de mostrar a necessidade do uso de roupas especiais para a prática de exercícios físicos e esportes. Em artigo intitulado "O vestuário e a moda em face da higiene", assinado pelo médico Dr. Eugenio Coutinho, em seus números 52 e 53, de 1941, Educação Física: Revista de Esporte e Saúde debate a necessidade do uso de roupas especiais para a prática de exercícios físicos e esportes, acentuando seu uso como fator de saúde e de higiene (p. 34-35 e p. 44-45).

Ainda nesse mesmo tema, as roupas foram também lembradas pelo médico Renato Kehl, em artigo publicado nesta mesma revista, no número 61, de 1941. O artigo, intitulado "O banho", traz inúmeras indicaçôes positivas acerca do banho como medida higiênica, bem como faz alusão ao banho de mar, atividade para a qual prescreve o uso de roupas especiais, afirmando que "[...] A roupa deve ser de lã e as horas mais convenientes são as compreendidas entre as 6 e 9 [horas] da manhã e entre 3 e 5 da tarde. Não se deve permanecer na água mais de 20 minutos e nem ficar tiritando de frio na praia" (p. 26-27).

15. LAVER, James. A roupa e a moda: uma história concisa. São Paulo: Companhia das Letras, 1989. Este autor mostra como este fato abalou o establishment secular na Europa e nos EUA e como até leis foram criadas para impedir o uso de saias curtas, na tentativa de impor uma moralidade própria (p. 232-233).

Pro-Posições, Campinas, v. 22, n. 3 (66), p. 81-96, set./dez. 2011 
Um mundo mais especializado e atravessado por discursos de natureza científica alcançou, de maneira notável, a prática de exercícios físicos e de esporte, sendo a roupa, os calçados, assim como outros artefatos a ela destinados, objetos privilegiados de atenção ${ }^{16}$. Se o ato de vestir-se de maneira especial para atividades distintas já era algo dado nesse período, sua extensão para as práticas corporais e esportivas foi uma novidade que pôs em xeque valores, ultrapassou fronteiras, libertou e oprimiu corpos em movimento. Praticar exercícios físicos ou algum esporte exigia mais que habilidade e vontade, exigia elegância.

O que seria pertinente sublinhar é o fato de que, mesmo que o número de praticantes não seja significativo no Brasil do período aqui analisado, a emulação criada pela valorização do corpo em movimento e do uso de roupas especiais para a prática de esporte e de exercícios físicos foi vigorosa e um estilo de vida afirmou-se. Usar roupas inspiradas em modelos esportivos é algo que foi lentamente ganhando espaço ao longo do período estudado, para afirmar-se em décadas posteriores, quando uma verdadeira indústria de roupas e materiais esportivos se instalou no Brasil.

Para os propósitos deste artigo, caberia tão somente concluir, afirmando que a roupa especial destinada aos exercícios físicos e ao esporte se insere naquilo que Roche (1997) afirmou em relação às roupas em geral, ou seja, faz parte de uma história das coisas banais. História que, longe de ser desprezível, ou, ainda, menor, pode constituir-se em importante trecho de nossa compreensão acerca de uma educação do corpo.

\section{Referências bibliográficas}

\section{Fontes}

Sport Illustrado, ano I, n. 2, abr. 1938

Sport Illustrado, ano I, n. 3, abr. 1938

Sport Illustrado, ano I, n. 6, maio 1938

Sport Illustrado, ano I, n. 17, ago. 1938

Sport Illustrado, ano I, n. 18, ago. 1938

Revista Educação Physica, n. 1, maio 1932

Revista Educaşão Física, n.16, mar. 1938

Revista Educação Física, n. 38, jan. 1940

Revista Educaşão Física, n. 46, set. 1940

16. Ver, a respeito, SOARES, C. L. (2008); SOARES, C.L. (20 I 0). 
Revista Educação Física, n. 52, mar. 1941

Revista Educação Física, n. 53, abr. 1941

Revista Educação Física, n. 61, dez. 1941

Revista Educação Física, n. 64, mar. 1941

\section{Demais referências}

ANDRIEU, B. Histoire du bronzage. Naissance du plaisir de la peau. Paris: CNRS, 2008.

ANDRIEU, B. et al. La peau : enjeu de société. Paris : Éditions du CNRS, 2008. p. 81 97.

BALZAC, H. Tratado dos excitantes; fisiologia do vestir; fisiologia gastronômica. São Paulo: Landy, 2004.

BARD, C. Une histoire politique du pantalon. Paris: Seuil, 2010.

BARTHE-DELOIZY, F. Géographie de la nudité: être nu en quelque part. [s. 1.]: Editions Bréal, 2003.

BEAURDRY, M. C.; COOK, L. J.; MROZOWSKI, S. A. Artefatos e vozes ativas: cultura material como discurso social. Vestígios - Revista Latino-Americana de Arqueologia Histórica - FAFICH-UFMG, Belo Horizonte, v. 1, n. 2, p. 71-116, jul./dez. 2007.

BENJAMIN, W. Passagens. Belo Horizonte: Editora UFMG; São Paulo: Imprensa Oficial do Estado de São Paulo, 2007.

BIBLIA SAGRADA. Antigo e Novo Testamento. 2. ed. São Paulo: Sociedade Bíblica do Brasil, 1993.

BOLOGNE, J-C. Histoire de la pudeur. Paris: Olivier Orban, 1986.

BOREL, F. Le vêtement incarné: les métamorphoses du corps. Paris: Calmman Lévy, 1992.

BOURDIEU, P. A distinção. São Paulo: Edusp; Porto Alegre: Zouk, [1979] 2007.

BRAUDEL, F. Escritos sobre a história. São Paulo: Perspectiva, [1969] 1992.

CRANE, D. A moda e seu papel social: classe, gênero e identidade das roupas. São Paulo: SENAC, 2006.

DEMENY, G. Education et harmonie des mouvements. 7. ed. Paris: Librarie Felix Alcan, [1911] 1920.

DESLANDRES, Y. Les modes vestimentaires dans la société occidentale. In: POIRER, J (Dir.). Histoire des moeurs: les coordonnées de l'homme et la culture matérielle. Paris: Gallimard, ano 1, v. 2, 1990. p. 1033-1702.

HOLLANDER, A. O sexo e as roupas. Rio de Janeiro: Rocco, 1996. 
JAMAIN, S. Les vêtements sportif des femmes des “années folles” aux années 1960: de la trangression à la "neutralisation" du genre. In: ROGER, A.; TERRET, T. Sport et genre: objets, arts et médias. Paris: L'Harmattan, 2005. v. 4.

JAMAIN, S.; TERRET, T. Fabricants, détaillants et vendeurs: l'économie du costume de sport à la Belle Époque. Revue STAPS (Revue Internationale du sport et de l'éducation physique), Bruxelles — éditions De Boeck, n. 83, p. 55-67, 2009.

LANOË, C. La poudre et le fard: une histoire des cosmétiques de la renaissence aux Lumières. Lonrai: Camps Vallon, 2008.

LAVER, J. A roupa e a moda: uma história concisa. São Paulo: Companhia das Letras, 1989.

LUCENA, R. F. de. O esporte na cidade. Campinas: Autores Associados, 2001.

MELO, V. A. de. Cidade Sportiva. Rio de Janeiro: Relume Dumará; Faperj, 2001.

MELO, V. A. de. Moda. Dicionário do esporte no Brasil. Campinas: Autores Associados, 2007. 116p.

MELO, V. A. de. Corpos, bicicletas e automóveis: outros esportes na transição do século XIX e XX. In: DEL PRIORE, M.; MELO, V. A. de. História do esporte no Brasil: do Império aos dias atuais, 2009. p. 71-105.

MONNEYRON, F. La mode et ses enjeux. Paris: Klincksieck, 2005.

MOTTIAUX, A. Nudité et vêtements: evolutions des symboles propres aux couriers/ euses à pied. In: ROGER, A.; TERRET, T. Sport et genre: objets, arts et médias. Paris: L'Harmattan, v. 4, p. 49-64, 2005.

OLIVA, M. Je n'ai rien à me mettre. In: MONNEYRON, F. (Dir.) Les vêtements. Paris: L'Harmattan, 2001. p. 69-84.

ORY, P. L’invention du bornzage. Bruxelles: Éditions Complexe, 2008.

ROCHE, D. La culture des apparences: une histoire du vêtements XVII-XVIIIème siècle. Paris: Fayard, 1989.

ROCHE, D. Histoire des choses banales: naissance de la consommation (XVII-XIXème siècle). Paris: Fayard, 1997.

SANT'ANNA, D. História do conforto na cidade de São Paulo. Anos 90 - Revista do programa de Pós-Graduação em História da UFRGS, n. 14, p. 162-183, dez. 2000.

SIMMEL, G. Philosophie et Sociologie de la modernité. Paris: Payot, 1989. t. 1.

SIMMEL, G. Filosofia da moda e outros escritos. Lisboa: Texto \& Grafia, [1905] 2008.

SOARES, C. L. Vêtements. In: ANDRIEU, B.; BOËTSCH, G. (Dir.). Dictionnaire du corps. 2. ed. Paris: Editions du CNRS, 2008. p. 389-340.

SOARES, C. L. As roupas nas práticas corporais e esportivas: a educação do corpo entre o conforto, a elegância e a eficiência (1920-1940). Tese de Livre-Docência — Faculdade de Educação Física, Unicamp, Campinas, 2010. 
SOUZA NETO, S. de. "Educação Physica": Revista de Esporte e Saúde - Profissão, História e Sociedade. In: ENCONTRO REGIONAL DE HISTÓRIA - O lugar da História, 17., 6 a 10 de setembro de 2004, Campinas. Anais... ANPUH/SP-UNICAMP, Campinas, 2004. CD-ROM.

VIGARELLO, G. Histoire de la beauté: le corps et l'art d'embellir de la renaissance a nos jours. Paris: Seuil, 2002.

Recebido em 28 de março de 2011 e aprovado em 27 de maio de 2011. 